\title{
Maternal supplementation with LGG reduces vaccine-specific immune responses in infants at high-risk of developing allergic disease
}

\author{
Paul V. Licciardi ${ }^{1,2}$, Intan H. Ismail ${ }^{1}$, Anne Balloch ${ }^{1}$, Milton Mui ${ }^{1}$, Edwin Hoe ${ }^{1}$, Karen Lamb ${ }^{3}$ and \\ Mimi L. K. Tang ${ }^{1,2,4 *}$
}

\author{
${ }^{1}$ Allergy and Immune Disorders, Murdoch Childrens Research Institute, Melbourne, VIC, Australia \\ ${ }^{2}$ Department of Paediatrics, University of Melbourne, Melbourne, VIC, Australia \\ ${ }^{3}$ Clinical Epidemiology and Biostatistics Unit, Murdoch Childrens Research Institute, Melbourne, VIC, Australia \\ ${ }^{4}$ Allergy and Immunology, Royal Children's Hospital, Melbourne, VIC, Australia
}

\section{Edited by:}

Virgil Schijns, Wageningen University, Netherlands

\section{Reviewed by:}

Dennis Klinman, National Institutes of Health, USA

Fabio Bagnoli, Novartis Vaccines, Italy

${ }^{*}$ Correspondence:

Mimi L. K. Tang, Allergy and Immune Disorders Group, Murdoch Childrens Research Institute, 50 Flemington Road, Melbourne, VIC 3052, Australia e-mail: mimi.tang@rch.org.au
Probiotics are defined as live micro-organisms that when administered in adequate amounts confer a health benefit on the host. Among their pleiotropic effects, inhibition of pathogen colonization at the mucosal surface as well as modulation of immune responses are widely recognized as the principal biological activities of probiotic bacteria. In recent times, the immune effects of probiotics have led to their application as vaccine adjuvants, offering a novel strategy for enhancing the efficacy of current vaccines. Such an approach is particularly relevant in regions where infectious disease burden is greatest and where access to complete vaccination programs is limited. In this study, we report the effects of the probiotic, Lactobacillus rhamnosus GG (LGG) on immune responses to tetanus, Haemophilus influenzae type $b(\mathrm{Hib})$ and pneumococcal conjugate (PCV7) vaccines in infants. This study was conducted as part of a larger clinical trial assessing the impact of maternal LGG supplementation in preventing the development of atopic eczema in infants at high-risk for developing allergic disease. Maternal LGG supplementation was associated with reduced antibody responses against tetanus, Hib, and pneumococcal serotypes contained in PCV7 ( $N=31)$ compared to placebo treatment $(N=30)$ but not total lgG levels. Maternal LGG supplementation was also associated with a trend to increased number of tetanus toxoid-specific $T$ regulatory in the peripheral blood compared to placebo-treated infants. These findings suggest that maternal LGG supplementation may not be beneficial in terms of improving vaccine-specific immunity in infants. Further clinical studies are needed to confirm these findings. As probiotic immune effects can be species/strain specific, our findings do not exclude the potential use of other probiotic bacteria to modulate infant immune responses to vaccines.

Keywords: vaccine, LGG, probiotic, pneumococcal, Treg, immune modulation

\section{INTRODUCTION}

The success of vaccination as a public health measure is best illustrated by the substantial reductions in rates of infectious diseases such as smallpox, polio, tetanus, and diphtheria following the introduction of these vaccines in the early part of the nineteenth century (1). Since that time, vaccination remains one of the most cost-effective health care intervention tools, and global vaccination rates are above $80 \%$ in most developed countries (2). The efficacy of vaccines is the result of a combination of factors that include the effectiveness of the specific vaccine, the type of adjuvant included in the vaccine and the achievement of vaccine delivery (completion of recommended schedule) which is in turn influenced by cost and feasibility of route of administration. The term adjuvant comes from the latin "adjuvare" meaning "to help." Adjuvants are critical components of vaccines as they help the immune system respond to the vaccine by several proposed mechanisms such as immunomodulation, cytokine regulation as well as depot formation, which allows for sustained release at the site of injection to maintain a continual source of immune stimulation $(3,4)$.

Despite these achievements, there are a number of significant challenges that remain. In particular, many children (and adults) living in developing countries still die from vaccine-preventable diseases such as tetanus, pneumococcal disease and rotavirus (5). In the last 10 years, international organizations such as the GAVI Alliance have made a profound impact on child health by improving access and delivery of these life-saving vaccines (6). Continued effort is required to reduce the burden of infectious disease in these settings and it is likely that the combination of increased vaccine coverage as well as the development of novel vaccines and adjuvants will be critical in reducing vaccine-preventable disease globally.

The identification of novel vaccine adjuvants have been the subject of intense scientific research over many decades. Particularly 
important is their activity at the mucosal surface as well as their ability to target both systemic and mucosal immunity, since most infections occur via the mucosal surface (7). Protection by current vaccines typically relies on recommended schedules that consist of multiple dosing over the first 1-2 years of life. In resourcelimited settings, this represents significant challenges in terms of cost and delivery. Adjuvants demonstrated to enhance immunological activity may allow for reduced vaccine dosing in these regions and could be given earlier to protect infants against initial colonization by pathogenic bacteria such as the pneumococcus. The mechanisms of action of current human approved adjuvants such as alum are controversial and have several limitations (8). Many candidate adjuvants have been studied, but only very few are approved for human use due to toxicity issues or a lack of immunogenicity. Therefore, novel adjuvants that can overcome these limitations are required. In recent times, the use of probiotic bacteria as immunomodulators has been investigated owing to their pleiotropic biological effects. Probiotics are defined as "live micro-organisms which when administered in adequate amounts, confer a health benefit on the host" (9). The immunomodulatory activities of probiotic bacteria make them potentially useful candidates as novel adjuvants for human vaccines that require further research.

The most well characterized probiotics include those of the Lactobacillus or Bifidobacterium species (10). These probiotics have been shown to be safe in humans and animals in a number of studies. In particular, the probiotic Lactobacillus rhamnosus GG (LGG) is reported to have a number of immune-modulating effects, including cytokine responses, enhancing protective IgG and IgA levels as well upregulating certain immune cell populations $(11,12)$. Moreover, LGG has been reported in a limited number of studies to enhance certain vaccine-specific responses $(13,14)$. Maternal intervention has been one approach to investigate the potential beneficial effects of probiotics such as LGG on increasing early-life protection. In this study, we examined the capacity for the probiotic LGG to enhance immune responses in infants that were part of a larger phase II maternal LGG intervention study for the prevention of allergic disease. Responses to the common childhood vaccines tetanus, Haemophilus influenzae type $\mathrm{b}$ and the pneumococcal conjugate vaccine (PCV7) were measured as well as total IgG levels.

\section{MATERIALS AND METHODS \\ STUDY SAMPLES}

Plasma and peripheral blood mononuclear cells (PBMCs) samples used in this study were collected from infants of mothers $(n=250)$ that were part of a randomized controlled trial of prenatal LGG for the prevention of eczema (Probiotic Eczema Prevention Study registered with Cochrane Skin Group www.nottingham.ac.uk/ ongoingskintrials Trial No. 36) (15). This study was approved by both the Royal Children's Hospital and Mercy Hospital for Women Research Ethics Committees and all participants gave written informed consent. Mothers were randomized to receive $1.8 \times 10^{10}$ colony forming units LGG (American Type Culture Collection 53103; Dicofarm, Italy) each morning from 36 weeks gestation until delivery, or maltodextrin placebo. At 12 months of age, blood samples $(5-10 \mathrm{ml})$ were collected from infants and in this study, the adjuvant effect of LGG was examined in plasma and PBMC samples collected from infants whose mothers were given LGG $(N=31)$ or placebo $(N=30)$. Participants, clinical trial and laboratory staff were blinded to treatment allocations and immunological assays throughout the study.

\section{MEASUREMENT OF TETANUS AND HIb ANTIBODY RESPONSES FOLLOWING VACCINATION}

Plasma concentrations of IgG antibodies against $H$. influenzae type $b$ polysaccharide were measured by ELISA using a previously published method (16). 96-well microtiter plates were coated with $H$. influenzae type b polysaccharide conjugated to human serum albumin (BEI Resources, Manassas, VA, USA) overnight at $4^{\circ} \mathrm{C}$. The standard anti-Hib polysaccharide serum (Lot 1983, FDA, USA), control anti-Hib human reference serum (NIBSC, UK) and infant samples were added to coated ELISA plates and incubated for $2 \mathrm{~h}$. Horseradish peroxidase-conjugated sheep anti-human IgG (Chemicon, Australia) was used as the detection antibody and a 3.3' ${ }^{\prime}$ 5.5' -tetramethylbenzidine (TMB) substrate solution (KPL, Gaithersburg, MD, USA) was used for detection. Optical densities were read on a microplate reader at $450 \mathrm{~nm}$ (reference filter $630 \mathrm{~nm}$ ) and converted to $\mu \mathrm{g} / \mathrm{ml}$ using $\mathrm{KC}$ Junior software (Bio-Tek Instruments Inc., USA).

A commercially available ELISA kit (Genzyme Virotech GmbH, Rüsselsheim, Germany) was used to quantitate plasma concentrations of IgG against tetanus toxoid (TT).

\section{MEASUREMENT OF PNEUMOCOCCAL ANTIBODY RESPONSE FOLLOWING PCV7}

Plasma levels of pneumococcal serotype-specific IgG were measured using a modified WHO-recommended method (17). Briefly, serotype-specific pneumococcal polysaccharides [American Type Culture Collection (ATCC), USA] were diluted in PBS and adsorbed (coated) onto medium-binding plates (Greiner, Germany) at $37^{\circ} \mathrm{C}$ for $5 \mathrm{~h}$ and then stored at $4^{\circ} \mathrm{C}$ overnight $(\mathrm{O} / \mathrm{N})$. Plates were blocked with phosphate-buffered saline containing $10 \%(\mathrm{v} / \mathrm{v})$ Fetal Calf Serum (PBS/FCS) and incubated at $37^{\circ} \mathrm{C}$ for $1 \mathrm{~h}$. Plasma and control samples were diluted 1:100 in a double absorption buffer of PBS/FCS containing cell-wall polysaccharide (CPS; $10 \mu \mathrm{g} / \mathrm{ml})$ and serotype $22 \mathrm{~F}(30 \mu \mathrm{g} / \mathrm{ml})$ and incubated overnight at $4^{\circ} \mathrm{C}$. A standard serum 89-SF (Food and Drug Administration, USA) was pre-absorbed with CPS only. Following washing of ELISA plates with PBS containing $0.05 \%(\mathrm{v} / \mathrm{v})$ Tween 20 (PBS-T), serial dilutions of the preabsorbed 89 -SF standard, control, and plasma samples were added and incubated at $37^{\circ} \mathrm{C}$ for $2 \mathrm{~h}$. Plates were washed with PBS$\mathrm{T}$ and a horseradish peroxidase-conjugated sheep anti-human IgG (Chemicon, Australia) was added and incubated at $37^{\circ} \mathrm{C}$ for $2 \mathrm{~h}$ followed by a further wash step with PBS-T. The reaction was developed by incubation with a TMB substrate solution for $9 \mathrm{~min}$ and stopped by the addition of $1 \mathrm{M}$ phosphoric acid. Absorbance at $450 \mathrm{~nm}$ (630 nm reference filter) was measured using a microplate reader (Bio-Tek, USA). Pneumococcal serotype-specific IgG concentrations for each sample were derived from the 89-SF standard values and expressed in microgram per milliliter using KC Junior software (Bio-Tek Instruments Inc., USA). 


\section{MEASUREMENT OF TOTAL IgG LEVELS IN SERUM}

96-well medium-binding microtiter plates (Greiner, Germany) were coated with $50 \mathrm{ng} / \mathrm{ml}$ of unlabeled human IgG (Southern Biotechnology, USA) diluted in carbonate-bicarbonate buffer, $\mathrm{pH}$ 9.6 overnight at $4^{\circ} \mathrm{C}$. Plates were then blocked with $5 \%(\mathrm{w} / \mathrm{v})$ skim milk powder in PBS-T for $1 \mathrm{~h}$ at RT followed by incubation of standards, serum samples, and controls for $2 \mathrm{~h}$ at RT. Level of IgG in serum samples were detected using a 1:5000 dilution of a sheep anti-human IgG-HRP reagent for a further $2 \mathrm{~h}$ at RT and developed with a TMB substrate solution for $7 \mathrm{~min}$ at RT. Reactions were stopped with the addition of $1 \mathrm{M}$ phosphoric acid and absorbance at $450 \mathrm{~nm}$ (630 nm reference filter) was measured using a microplate reader (Bio-Tek, USA). The amount of total $\mathrm{IgG}$ in serum samples were derived from the standard curve (inhouse control) and expressed in microgram per deciliter using $\mathrm{KC}$ Junior software (Bio-Tek Instruments Inc., USA).

\section{PERIPHERAL BLOOD MONONUCLEAR CELL ISOLATION AND CULTURE}

Blood samples $(5-10 \mathrm{ml})$ were collected from infants at 12 months of age into preservative-free sodium heparin tubes. PBMCs were separated from heparinized blood by density gradient centrifugation (Ficoll-Paque, Sweden) within $8 \mathrm{~h}$ of collection and rate frozen at a concentration of $8-10 \times 10^{6}$ cells $/ \mathrm{ml}$. PBMCs were thawed rapidly at $37^{\circ} \mathrm{C}$, washed in RPMI-1640 medium (Gibco, Grand Island, NY, USA) and re-suspended at $1 \times 10^{6}$ cells $/ \mathrm{ml}$ for culture. Thawed PBMC were cultured in AIM-V serum free medium (Gibco, Grand Island, NY, USA) supplemented with $4 \times 10^{-5} \mathrm{M}$ of 2-Mercapethanol (2-ME; Gibco, Grand Island, NY, USA) and stimulated with TT $(1 \mu \mathrm{g} / \mathrm{ml})$ or left in medium alone (with 2-ME; unstimulated) for 6 days at $37^{\circ} \mathrm{C}$ in $5 \% \mathrm{CO}_{2}$ in air.

\section{ENUMERATION OF Treg IN PBMCS BY FLOW CYTOMETRY}

After 6 days of culture, PBMCs were centrifuged at $600 \mathrm{~g}$ for $10 \mathrm{~min}$ at room temperature and supernatants removed. Cell pellets were stained with fluorochrome-conjugated monoclonal antibodies in $50 \mu \mathrm{l}$ staining volumes. CD3-allophycocyanin (APC), CD4-peridinin chlorophyll protein (PerCP), CD25-phycoerythrin (PE)-Cy7 (BD Bioscience, San Jose, CA, USA) and forkhead box P3 (FoxP3)-PE (e-Bioscience, San Diego, CA, USA) were used to identify CD25 ${ }^{\text {hi }}$ FoxP $3{ }^{\text {hi }} \mathrm{T}$ cell populations in PBMCs. The proliferative response to TT was evaluated in 6 day cultures using the cell tracking dye Carboxyfluorescein Diacetate Succinimidyl Ester (CFSE; 0.1 $\mu \mathrm{M}$ ). Non-proliferating cells were identified as $\mathrm{CFSE}^{\text {hi }}$ and proliferating cells as CFSE ${ }^{\text {lo }}$. Cells were washed once with PBS and incubated with fluorochrome-labeled antibodies or isotype controls in $50 \mu \mathrm{l}$ staining volumes for $30 \mathrm{~min}$. For intracellular staining, cells were subsequently permeabilized, fixed, and stained with FoxP3-PE antibody or isotype control according to the manufacturer's instructions (e-Bioscience). Data were acquired on a 4-color LSR II (BD, San Jose, CA, USA) and analyzed with FACSDiva v4.1 software using well-defined gating strategies. A minimum of 100,000 events were acquired in the lymphocyte gate.

\section{STATISTICAL ANALYSIS}

The Student's $t$-test was used to analyze normally distributed continuous data, and Mann-Whitney $U$-test was used for skewed data. Data were presented as either geometric means with 95\% confidence intervals (CI), or median with interquartile range (IQR) depending on the distribution. Frequency data was analyzed using the Fisher's exact test. A $p$-value $<0.05$ was considered statistically significant. Analyses were performed using GraphPad Prism Version 6 (GraphPad Software Inc., CA, USA). Linear regression models (or logistic regression when the outcome was binary) were used to adjust for potential confounders in Stata (StataCorp LP, USA) including the presence of IgE-associated eczema ever or at 12 months of age, atopy, and yogurt intake, as there were trends toward significance for these variables between the LGG and placebo groups.

\section{RESULTS STUDY COHORT}

A summary of the characteristics of study participants is presented in Table 1. No significant differences were found although there were trends toward a higher proportion of infants who were atopic ( 46.6 vs. $23.3 \% ; p=0.07)$ and had reported IgE-associated eczema ( 33.3 vs. $13.3 \% ; p=0.07$ ) in the LGG group compared to placebo (Table 1). No differences were found for any of the other characteristics.

\section{MATERNAL LGG SUPPLEMENTATION WAS ASSOCIATED WITH REDUCED VACCINE-SPECIFIC BUT NOT TOTAL IgG RESPONSES IN INFANTS}

We examined the impact of maternal LGG supplementation on the antibody response to a number of childhood vaccines in

Table 1 | Characteristics of study participants

\begin{tabular}{|c|c|c|}
\hline Characteristic & $\operatorname{LGG}(n=30)^{\mathrm{a}}$ & Placebo $(n=30)$ \\
\hline Infant eczema ever & $43.3 \%$ & $40 \%$ \\
\hline Infant eczema 12 months & $40 \%$ & $23.3 \%$ \\
\hline Infant IgE-eczema ever & $33.3 \%$ * & $13.3 \%$ \\
\hline Infant IgE-eczema 12 months & $33.3 \% *$ & $13.3 \%$ \\
\hline Atopy & $46.6 \% * *$ & $23.3 \%$ \\
\hline Paternal eczema & $22.6 \%$ & $21.4 \%$ \\
\hline Maternal eczema & $45.2 \%$ & $51.7 \%$ \\
\hline Sibling eczema & $86.4 \%$ & $60.9 \%$ \\
\hline Antibiotics during pregnancy & $29 \%$ & $23.3 \%$ \\
\hline $\begin{array}{l}\text { Daily yogurt intake during } \\
\text { pregnancy (g/week), median } \\
\text { (range) }\end{array}$ & $200(0-1400)^{* * *}$ & $600(0-1400)$ \\
\hline Maternal tertiary education & $83.3 \%$ & $72.4 \%$ \\
\hline Household smoker & $13.3 \%$ & $13.8 \%$ \\
\hline $\begin{array}{l}\text { Other children present in } \\
\text { household }\end{array}$ & $66.7 \%$ & $58.6 \%$ \\
\hline Infant sex - female & $33.3 \%$ & $38.7 \%$ \\
\hline Gestation (weeks), median (range) & $39.5(35.4-41.5)$ & $39.5(37.4-41.5)$ \\
\hline Birthweight (g), median (range) & $3300(2700-3975)$ & $3550(2770-5020)$ \\
\hline Cesarean delivery & $25.8 \%$ & $32.1 \%$ \\
\hline $\begin{array}{l}\text { Duration of breastfeeding in first } \\
\text { year (months), median (range) }\end{array}$ & $8.5(0-12)$ & $9(6-12)$ \\
\hline
\end{tabular}

${ }^{a}$ Characteristics unavailable for one infant.

${ }^{*} p=0.07 ;{ }^{*} p=0.06 ;{ }^{* *} p=0.05$ between LGG and probiotic groups. 


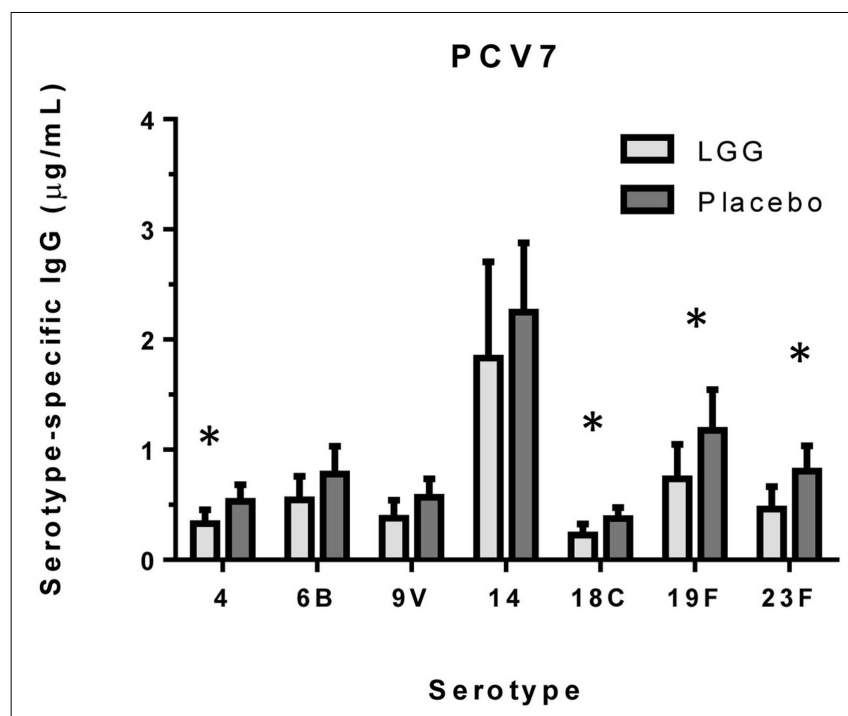

FIGURE 1 | Serotype-specific IgG levels (GMC $\pm 95 \% \mathrm{Cl}$ ) for infants in the LGG $(N=31)$ or Placebo $(N=30)$ groups following PCV7

immunization. ${ }^{*} p<0.05$ comparing $L G G$ and Placebo treatment.

infants at 12 months of age. There were significant differences in the unadjusted GMC for serotype-specific IgG to PCV7 serotypes $4(p=0.027), 6 \mathrm{~B}(p=0.040), 18 \mathrm{C}(p=0.032), 19 \mathrm{~F}(p=0.041)$, and $23 \mathrm{~F}(p=0.019)$ between the LGG and placebo-treated groups following immunization (Figure 1). Lower serotype-specific IgG levels were observed across all serotypes, with fold decreases of between 0.58 and 0.83 for serotypes $23 \mathrm{~F}$ and 14 , respectively in the LGG group relative to the placebo group. After adjustment for eczema status, a significant difference still remained for each of these serotypes while adjustment for atopy resulted in the serotype-specific IgG response for $9 \mathrm{~V}$ also becoming significant ( $p=0.040$; Table A1A in Appendix). Yogurt intake did not affect the PCV7 response after adjustment (Table A1B in Appendix).

In addition, there was a significantly lower proportion of infants with serotype-specific IgG antibody titers $>0.35 \mu \mathrm{g} / \mathrm{ml}$ (indicative of a protective response post-PCV7) in the LGG group compared to placebo for four of the seven serotypes in PCV7 (serotypes $4,9 \mathrm{~V}, 18 \mathrm{C}$, and $23 \mathrm{~F}$, all $p<0.05$; Figure $2 \mathrm{~A}$ ). However, using a cut off of $1.0 \mu \mathrm{g} / \mathrm{ml}$ of serotype-specific IgG, there were no differences between infants of LGG and placebo-treated mothers (although there was a trend for serotype 19F; $p=0.058$ ) (Figure 2B). Adjustments for eczema status, atopy, or yogurt intake did not alter the conclusions reached about the impact on this response (Tables A2A,B and A3A,B in Appendix).

Plasma levels of anti-tetanus toxoid IgG were also significantly reduced in infants of mothers treated with LGG compared to infants of placebo-treated mothers, with unadjusted GMCs of 0.96 and $0.51 \mathrm{IU} / \mathrm{ml}(p=0.042)$ in the LGG and placebo treatment groups respectively, representing a 1.9-fold difference between groups (Figure 3A). After adjustment for each of the potential confounders, the observed association weakened but remained statistically significant $(p<0.05)$ for all variables other than IgEassociated eczema at 12 months of age ( $p=0.052$; Tables A1A,B

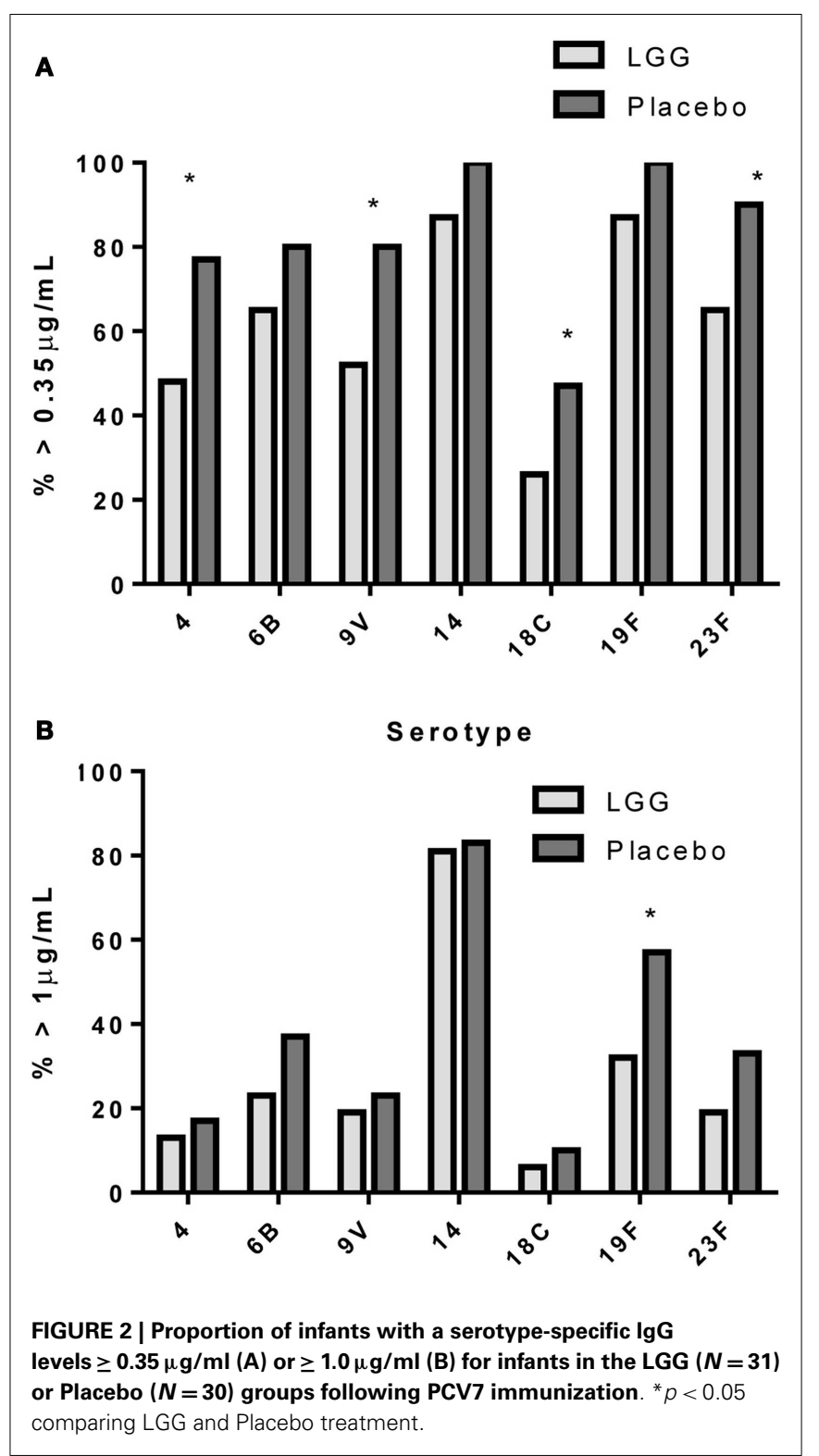

in Appendix). Similarly, reduced anti-Hib IgG levels were also found in the LGG group compared with placebo, with GMCs of 3.96 and $2.35 \mu \mathrm{g} / \mathrm{ml}$, respectively, although this was not significant (Figure 3B). Similarly, adjustment for each of the variables weakened this association but did not affect the conclusions about differences between LGG and placebo (Tables A1A,B in Appendix). However, LGG supplementation did not have any effect on total IgG levels in the serum of these infants (Figure 4).

\section{MATERNAL LGG SUPPLEMENTATION WAS ASSOCIATED WITH INCREASED FREQUENCY OF TT-SPECIFIC Treg IN INFANTS AT 12 MONTHS OF AGE}

As LGG has been suggested to promote tolerogenic $T$ regulatory (Treg) responses, we investigated the effect of maternal LGG treatment on Treg responses to the vaccine antigen in infants at 12 months of age. There was a significantly higher number and 

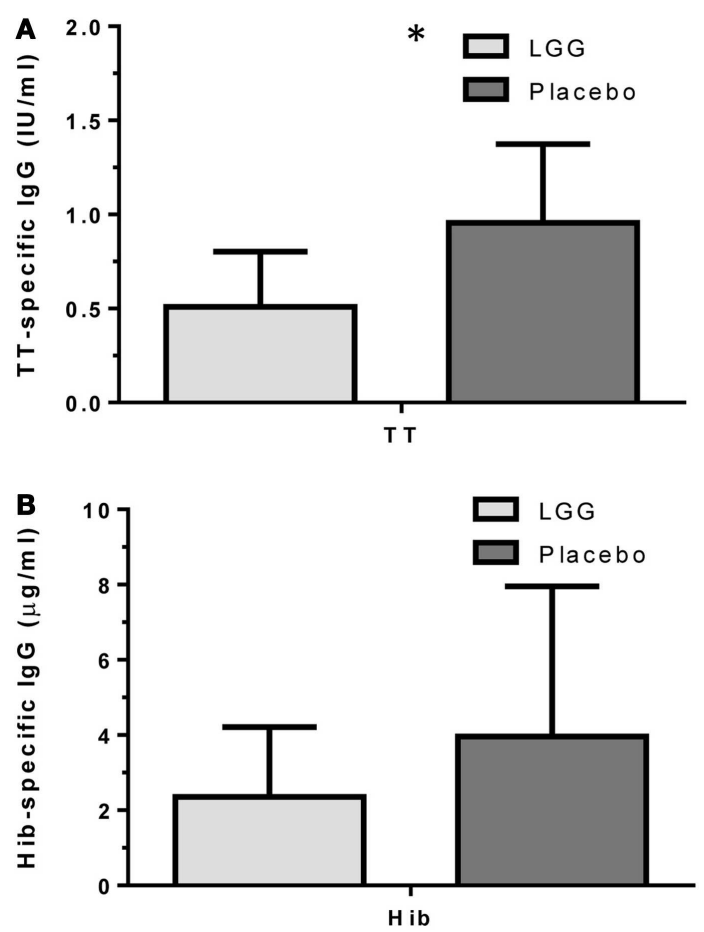

FIGURE 3 | Levels of (A) anti-TT IgG and (B) anti-Hib IgG (GMC $\pm 95 \%$ Cl) for infants in the LGG $(N=31)$ or Placebo $(N=30)$ groups following TT and Hib immunization. ${ }^{*} p<0.05$ comparing LGG and Placebo treatment.

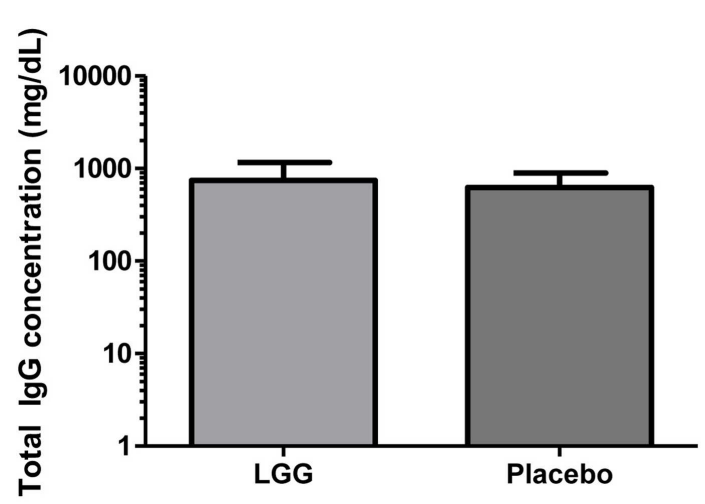

FIGURE 4 | Level of total IgG in the serum of infants (GMC $\pm 95 \% \mathrm{CI}$ ) in the LGG $(N=31)$ and Placebo $(N=30)$ groups.

percentage of TT-specific CD4 ${ }^{+}$T cells in infants of LGG-treated mothers compared to infants of placebo-treated mothers (4563 vs. $3505 ; p=0.027 ; 50.7$ vs. $35.6 \% ; p=0.016)$ after stimulation with TT (Figure 5). In addition, there was a non-significant increase in total Treg numbers following stimulation with TT in infants of LGG-treated mothers as compared to infants of placebo-treated mothers $(\mathrm{LGG}$ group $=407$ vs. placebo group $=305)$. This was also observed for Treg within both the proliferating CFSE ${ }^{\text {lo }}$ population of $\mathrm{CD}^{+}{ }^{+} \mathrm{T}$ cells (presumed TT-specific Treg; $\mathrm{LGG}=40$ vs. placebo $=21)$ as well as the non-dividing $\mathrm{CFSE}^{\text {hi }}$ population of $\mathrm{CD}^{+}{ }^{+} \mathrm{T}$ cells (presumed to be naive Treg that lack TCR specificity for TT; $L G G=362$ vs. placebo $=270$ ) (Figure 5). Only TT was measured for this response as this part of the panel investigated during the larger PEPS allergy trial as no PBMCs were available for additional analyses.

Measurement of cytokine responses to TT revealed no significant differences between infants in the LGG and placebo groups for any of the cytokines examined (Figure 6). Interestingly nevertheless, levels of TGF- $\beta$ produced by PBMCs from infants in the LGG group were noted to be almost two-fold higher than levels of infants in the placebo group (Figure 6).

\section{DISCUSSION}

This study reports that maternal supplementation with the probiotic L. rhamnosus GG (LGG) was able to reduce the levels of vaccine-specific antibodies in infants at 12 months of age. It was found that the IgG response to TT and PCV7 vaccines was significantly lower amongst infants of mothers treated with LGG during pregnancy. However no effects on the IgG response to Hib vaccine were observed. Moreover, total IgG levels were similar across the groups, and consistent with previous data (18), suggesting that maternal LGG may be able to modulate, directly or indirectly, specific immune responses in the infants. This is the first study to examine this immune-modulating potential of LGG when administered to mothers during pregnancy and includes a comprehensive evaluation of the immune response to a broad range of vaccine antigens.

In our study, LGG reduced the antibody response to all vaccines studied, with significant reductions observed for TT and four of seven PCV7 serotypes (4,18C, 19F, and 23F). There was also a reduced proportion of infants with protective IgG levels $(\geq 0.35 \mu \mathrm{g} / \mathrm{ml})$ to several PCV7 serotypes at 12 months of age. The effect of LGG on the anti-TT response was also associated with increased numbers of TT-specific Treg, although this was not statistically significant. The higher number of Treg - but not percentage of Treg in the $\mathrm{CD} 4^{+} \mathrm{T}$ cell population - is most likely a reflection of the significantly higher number and proportion of $\mathrm{CD}^{+}{ }^{+} \mathrm{T}$ cells in the LGG group compared to placebo. These data suggest that LGG may induce Th1 responses that are transferred to these allergic infants in early life, consistent with LGG's reported effects in allergy involving upregulated TT-specific $\mathrm{CD}^{+}{ }^{+}$Treg which may explain the lower TT-specific IgG levels observed in this study. In addition, the elevated (non-significant) TGF- $\beta$ levels in PBMC supernatants from infants in the LGG group also provide further support for a possible Treg-mediated effect for TT. It is possible that the relatively small sample size in this study may have precluded our ability to detect any real differences by LGG.

The infants in this study were part of a larger randomized, placebo-controlled trial for eczema prevention (termed PEPS) and were considered "high-risk" for the development of allergic disease. Maternal LGG supplementation in this study was not able to prevent the development of eczema in infants by 12 months of age compared to placebo treatment (15).

However, in this study, more infants had reported eczema or atopy in the LGG group compared to placebo and it is possible that the LGG effect on vaccine responses were in part due to their 

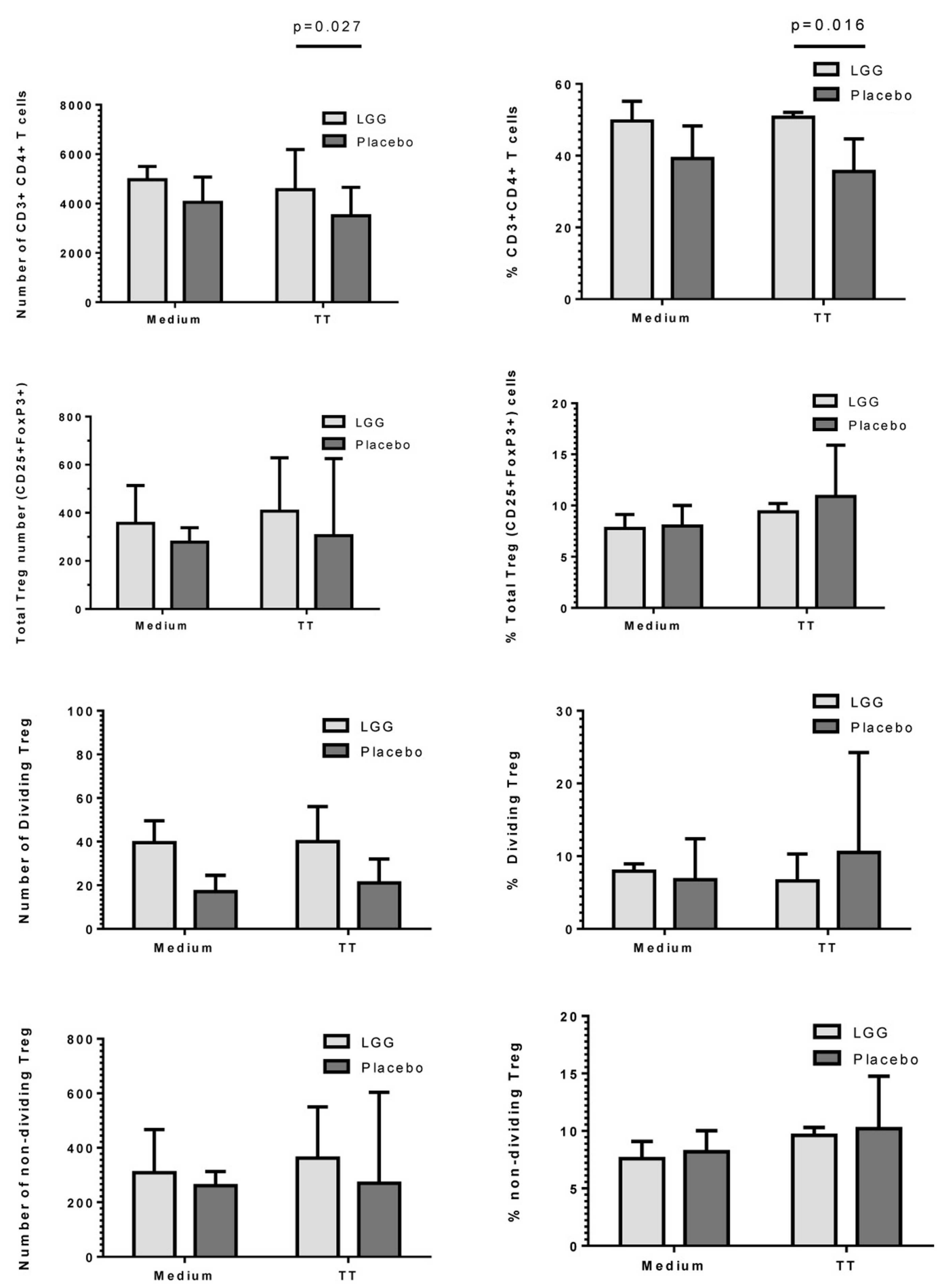

FIGURE 5 | Numbers and frequency (\%) of $\mathrm{CD3}^{+} \mathrm{CD4}^{+} \mathrm{T}$ cells, total $\mathrm{CD4}^{+} \mathrm{CD}^{+} 5^{+} \mathrm{FoxP3}^{+}$Treg, dividing $\left(\mathrm{CFSE}^{10}\right)$, and non-dividing (CFSE ${ }^{\text {hi }}$ ) Treg identified in PBMCs isolated from infants in the LGG $(\boldsymbol{N}=\mathbf{3 1})$ or Placebo $(\boldsymbol{N}=\mathbf{3 0})$ groups. PBMCs $\left(1 \times 10^{6} / \mathrm{ml}\right)$

were stimulated with TT $(1 \mu \mathrm{g} / \mathrm{ml})$ or unstimulated (medium) for 6 days at $37^{\circ} \mathrm{C}$ and $5 \% \mathrm{CO}_{2}$. Bars represent median + interquartile range (IQR). Significance determined using the Mann-Whitney U-test.

allergic status. In allergy, the immune system is dysregulated with a predominately Th2-biased response characterized by increased levels of IgE and cytokines such as IL-4 and IL-13 while IgG levels and Th1 cytokines such as IFN- $\gamma$ are reduced $(19,20)$. A shift toward Th2-based IgE responses in allergy is known to downregulate Th1-based IgG levels - which are typically induced following 

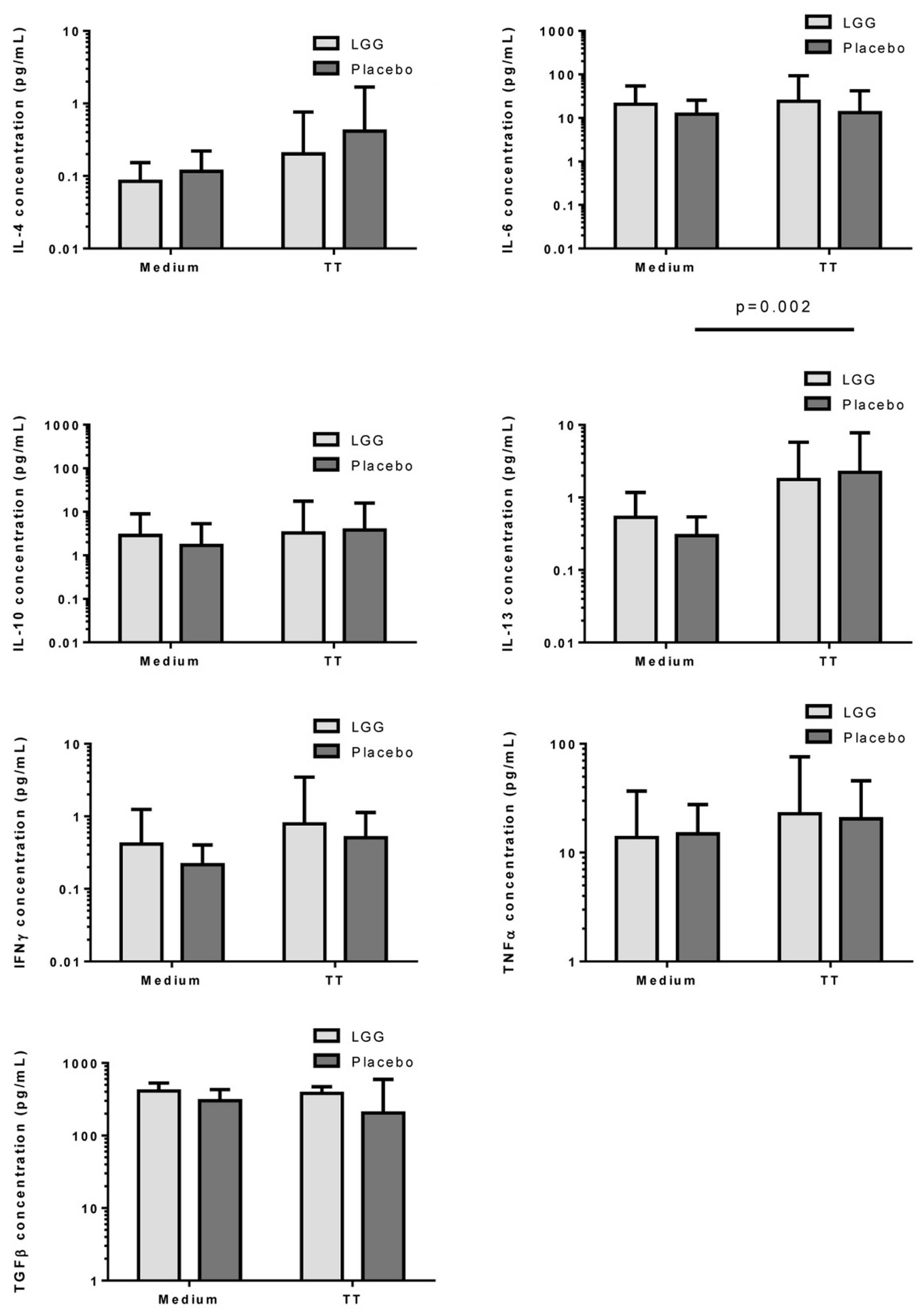

FIGURE 6 | Levels of IL-4, IL-6, IL-10, IL-13, IFN $\gamma$, TNF $\alpha$, and TGF $\beta$ in PBMC supernatants following stimulation with $\mathrm{TT}$ (1 $\mu \mathrm{g} / \mathrm{mI}$ ) or unstimulated (medium) for $\mathbf{6}$ days at $\mathbf{3 7}{ }^{\circ} \mathbf{C}$ and $\mathbf{5} \% \mathbf{C O}_{2}$. Bars represent $\mathrm{GMC} \pm 95 \% \mathrm{Cl}$.

vaccination - and so it may be possible that the vaccine-specific responses seen in the LGG group were a result of their allergic status rather than the probiotic itself. No differences were observed in relation to the Th1:Th2 balance between these groups despite a trend toward higher levels of the regulatory cytokine TGF- $\beta$ in the LGG group. However, following adjustment for eczema status and 
atopy, this effect for LGG persisted, indicating that allergic status did not bias these results. It is therefore likely that the effect of LGG was related to an induction of maternal tolerogenic responses that were transferred to the infant. The fact that maternal LGG did not reduce total IgG levels in the infant provides further support to the ability of LGG to modulate certain antigen-specific responses. The IgG response to an unrelated (non-vaccine) antigen was not undertaken in this study but is expected to be low in this cohort given the age of the infants and the relative lack of exposure to antigens other than those in the vaccines. This is best illustrated for pneumococcal vaccination, whereby infants previously given three doses of PCV7 during infancy produce elevated IgG responses to vaccine serotypes but not non-vaccine serotypes at 12 months of age (21). Furthermore, the use of total IgG as a non-vaccine antigen control for TT-responses has been reported previously (22).

There are several mechanisms by which probiotics mediate their tolerogenic effects which may help to explain our results observed. A number of studies have reported that probiotics such as LGG are able to increase the number and function of allergenspecific Treg in mice (23) and humans (24). This may occur through direct cell-cell contact or via the release of regulatory cytokines such as TGF- $\beta$ and IL-10 (25-27) and are critical for the control of immune-mediated diseases (28) and have been reported to correlate with the amelioration of clinical allergy (2931). Maternal supplementation with probiotics has been shown to induce immunomodulatory effects in infants via cord blood, breast milk, or indirectly through changes to intestinal microbiota $(32,33)$. We recently reported that LGG reduced the levels of TGF$\beta$ and total IgA in breast milk (34) which may explain the lack of effect against allergic disease. It is possible that the maternal LGG was transferred to the infants in this study resulting in changes to the intestinal microbiome. It is now known that the microbiome is a critical factor in shaping the infant immune system by providing essential signals that drive healthy immune development (35).

Probiotics have also been increasingly used as a strategy to restore intestinal dysbiosis that is associated with allergic disease. Early-life interactions between intestinal microbiota and the immune system is critical for the development of a healthy immune system (36). Altered microbiota containing fewer beneficial bacteria are suggested to provide inappropriate signals to mucosal immune cells leading to aberrant inflammatory responses and a loss of immune regulation. Studies have reported that prenatal and/or postnatal probiotic treatment with various Lactobacillus and Bifidobacterium species improved microbiota patterns (37, 38). Moreover, data from meta-analyses on the ability of probiotics to prevent allergic diseases are inconclusive, owing predominately to the heterogeneity in the study designs and probiotic used (39, 40). However, prenatal probiotic treatment has shown the most promise in this context (41), suggesting that early-life signals are important in immune development. It is possible that LGG transfer from mother to infant may explain the immunomodulatory effect for LGG in this study. Indeed, in the PEPS study, maternal supplementation with LGG increased the numbers of the beneficial bacteria B. longum (42) which are important for healthy immune development. Investigations are currently ongoing as to whether the presence of B. longum influenced the Th1:Th2 balance in these infants at 12 months of age. It is possible that such early-life influences on microbiota may impact on the immune response to vaccines, particularly in the first 6 months of life. Indeed, it is now recognized that the intestinal microbiome should be considered when developing vaccines specific for certain geographical regions and populations since vaccine efficacy may vary based on the microbial composition of the gastrointestinal system (43).

More recently, the use of probiotics as novel vaccine adjuvants has been investigated (44). Infants treated with LGG at 2-5 months of age had an elevated (but not significant) serum IgA and IgM response following an oral rotavirus vaccine, as well as significantly higher numbers of rotavirus-specific IgM secreting cells compared to placebo (13). LGG was also shown to enhance neutralizing antibody titers as well as serum poliovirus-specific IgG and IgA in adults immunized with the trivalent oral polio vaccine (OPV) compared to placebo (45). In another study, a greater proportion of LGG-treated adults had higher numbers of Typhi-specific IgA secreting cells (ASCs) following oral S. typhi Ty21a immunization despite no differences in the specific antibody response (46). In addition, probiotics have been shown to elicit adjuvant properties following immunization with other vaccines such as influenza (14, 47, 48), Hep B (49), and polio (50).

The identification of novel adjuvants that can be administered in early-life would provide a substantial benefit in settings of high infectious disease burden. The contribution of the pneumococcus, Hib, and tetanus to neonatal and infant mortality is considerable, with more than two million deaths each year $(51,52)$. Furthermore, in developing countries, vaccine delivery is a significant problem where access to complete vaccination schedules is limited or where drop-out rates are high (53). Therefore probiotics potentially offer substantial advantages as vaccine adjuvants in terms of safety, ease of administration and their demonstrated ability to enhance immune responses. The reduced proportion of protective antibody levels in the LGG group may pose a theoretical increased risk of disease susceptibility which would be particularly important in high burden of disease settings. However, as this study was not designed to specifically address the effect of probiotics on vaccine responses, further large scale randomized trials are required to fully evaluate this effect.

A major strength of this study is the comprehensive evaluation of LGG's capacity to modulate infant vaccine responses following maternal supplementation, involving pneumococcal, Hib, and TT-specific immune responses. In addition, this is one of the first studies to describe the adjuvant effect of probiotics for PCV7 using WHO-based assays. However, several limitations need to be addressed. This is a relatively small cohort and so caution must be applied when considering the results of this study. The effect of multiple comparison testing cannot be excluded and in this study was not performed due to the small sample size. Furthermore, this study may not be adequately powered to detect a beneficial impact of LGG on infant vaccine responses given the primary outcome was clinical allergy at 12 months of age. Also, maternal LGG supplementation may not be as effective as a combined prenatal/postnatal or postnatal alone approach for examination of the infant immune response to vaccines as has been shown for studies of allergic disease (10). Moreover, all vaccinations were administered as part of the 3-dose National Immunization Program in Australia which might not be optimal to detect any differences in these responses, as 
all recipients would be expected to respond robustly to this schedule (54). Examination of earlier post-vaccination time-points may have potentially revealed important differences by LGG. It is also possible that probiotics other than LGG may be more beneficial in this setting since it is known that the activities of probiotics are dependent on the species and strain used (18). Subsequent studies in a larger healthy cohort will be important in understanding the potential benefits of probiotics in modulating vaccine-specific immune responses during early-life.

\section{CONCLUSION}

The probiotic LGG was found to reduce the antibody levels specific for TT, PCV7, and Hib but not total IgG in infants at 12 months of age who were part of a maternal supplementation trial for the prevention of allergic disease. These results suggest that this probiotic may not be beneficial in relation to improving vaccine-specific responses in these infants. Various factors may have impacted on this response such as the nature of the cohort, timing of probiotic administration, or the probiotic itself. Therefore additional studies that are designed to specifically address these questions will be of significant interest, particularly in settings of high infectious disease burden and where access to complete vaccine schedules is limited.

\section{ACKNOWLEDGMENTS}

The studies were funded by grants from the Jack Brockhoff Foundation, the Murdoch Childrens Research Institute, the Australian National Health and Medical Research Council (NHMRC) and the Ilhan Food Allergy Foundation. This study was supported in part by the Victorian Government's Operational Infrastructure Support Program. Paul V. Licciardi is the recipient of a NHMRC Early Career Fellowship. Intan Ismail was supported by a scholarship from the Ministry of Higher Education, Malaysia and Universiti Putra Malaysia. LGG and placebo capsules were manufactured and supplied by Dicofarm Ltd. (Roma, Italy). The HbO-HA antigen for the Hib studies was obtained through the NIH Biodefense and Emerging Infections Research Repository, NIAID, NIH: $H$. influenzae type b oligosaccharide-Human Serum Albumin Conjugate (Hbo-HA Antigen), NR-122268. We thank Lam Kwang-Yang and Natalie Wei Ling Yeong for their help with the total IgG assays. We are grateful to the participating families and the midwifery staff of the Mercy Hospital for Women for their cooperation, to Michael Permezel, Kay Hynes, Christine Plover, Maggie Flood, Christine Axelrad, Sally Moore, Val Bryant, and Noel Cranswick for their assistance in the conduct of this trial, to Frances Oppedisano for her assistance with immunological studies and to John $\mathrm{Su}$ for advice regarding eczema assessment.

\section{REFERENCES}

1. Clemens J, Jodar L. Introducing new vaccines into developing countries: obstacles, opportunities and complexities. Nat Med (2005) 11(4 Suppl):S12-5. doi:10.1038/nm1225

2. Del Giudice G. Vaccination strategies. An overview. Vaccine (2003) 21(Suppl 2):S83-8. doi:10.1016/S0264-410X(03)00205-6

3. Schijns VE. Immunological concepts of vaccine adjuvant activity. Curr Opin Immunol (2000) 12(4):456-63. doi:10.1016/S0952-7915(00)00120-5

4. O'Hagan DT, De Gregorio E. The path to a successful vaccine adjuvant 'the long and winding road'. Drug Discov Today (2009) 14(11-12):541-51. doi:10.1016/j.drudis.2009.02.009
5. Amar J, Chabo C, Waget A, Klopp P, Vachoux C, Bermudez-Humaran LG, et al. Intestinal mucosal adherence and translocation of commensal bacteria at the early onset of type 2 diabetes: molecular mechanisms and probiotic treatment. EMBO Mol Med (2011) 3(9):559-72. doi:10.1002/emmm.201100159

6. Lob-Levyt J. Contribution of the GAVI Alliance to improving health and reducing poverty. Philos Trans R Soc Lond B Biol Sci (2011) 366(1579):2743-7. doi: $10.1098 /$ rstb. 2011.0040

7. Woodrow KA, Bennett KM, Lo DD. Mucosal vaccine design and delivery. Annu Rev Biomed Eng (2012) 14:17-46. doi:10.1146/annurev-bioeng-071811-150054

8. Kool M, Fierens K, Lambrecht BN. Alum adjuvant: some of the tricks of the oldest adjuvant. J Med Microbiol (2012) 61(Pt 7):927-34. doi:10.1099/jmm.0. 038943-0

9. WHO. Health and Nutritional Properties of Probiotics in Food Including Powder Milk with Live Lactic Acid Bacteria. (2001). Available from: www.who.int/ foodsafety/publications/fs_management/en/probiotics.pdf

10. Tang ML, Lahtinen SJ, Boyle RJ. Probiotics and prebiotics: clinical effects in allergic disease. Curr Opin Pediatr (2010) 22(5):626-34. doi:10.1097/MOP. 0b013e32833d 9728

11. Oelschlaeger TA. Mechanisms of probiotic actions - a review. Int J Med Microbiol (2010) 300(1):57-62. doi:10.1016/j.ijmm.2009.08.005

12. Hajela N, Nair GB, Ganguly NK. Are probiotics a feasible intervention for prevention of diarrhoea in the developing world? Gut Pathog (2010) 2(1):10. doi:10.1186/1757-4749-2-10

13. Youngster I, Kozer E, Lazarovitch Z, Broide E, Goldman M. Probiotics and the immunological response to infant vaccinations: a prospective, placebo controlled pilot study. Arch Dis Child (2011) 96(4):345-9. doi:10.1136/adc.2010. 197459

14. Rizzardini G, Eskesen D, Calder PC, Capetti A, Jespersen L, Clerici M. Evaluation of the immune benefits of two probiotic strains Bifidobacterium animalis ssp. lactis, BB-12 ${ }^{\circledR}$ and Lactobacillus paracasei ssp. paracasei, L. casei $431^{\circledR}$ in an influenza vaccination model: a randomised, double-blind, placebo-controlled study. Br J Nutr (2011) 107(6):876-84. doi:10.1017/S000711451100420X

15. Boyle RJ, Ismail IH, Kivivuori S, Licciardi PV, Robins-Browne RM, Mah LJ, et al. Lactobacillus GG treatment during pregnancy for the prevention of eczema: a randomized controlled trial. Allergy (2011) 66(4):509-16. doi:10.1111/j.13989995.2010.02507.x

16. Ritz N, Mui M, Balloch A, Curtis N. Non-specific effect of Bacille CalmetteGuerin vaccine on routine immunisations. Vaccine (2013) 31(30):3098-103. doi:10.1016/j.vaccine.2013.03.059

17. Balloch A, Licciardi PV, Leach A, Nurkka A, Tang ML. Results from an inter-laboratory comparison of pneumococcal serotype-specific IgG measurement and critical parameters that affect assay performance. Vaccine (2010) 28(5):1333-40. doi:10.1016/j.vaccine.2009.11.011

18. Stoop JW, Zegers BJ, Sander PC, Ballieux RE. Serum immunoglobulin levels in healthy children and adults. Clin Exp Immunol (1969) 4(1):101-12.

19. Williams CM, Rahman S, Hubeau C, Ma HL. Cytokine pathways in allergic disease. Toxicol Pathol (2012) 40(2):205-15. doi:10.1177/ 0192623311430694

20. Yagi R, Zhu J, Paul WE. An updated view on transcription factor GATA3mediated regulation of Th1 and Th2 cell differentiation. Int Immunol (2011) 23(7):415-20. doi:10.1093/intimm/dxr029

21. Russell FM, Licciardi PV, Balloch A, Biaukula V, Tikoduadua L, Carapetis JR, et al. Safety and immunogenicity of the 23 -valent pneumococcal polysaccharide vaccine at 12 months of age, following one, two, or three doses of the 7-valent pneumococcal conjugate vaccine in infancy. Vaccine (2010) 28(18):3086-94. doi:10.1016/j.vaccine.2010.02.065

22. Marchant A, Pihlgren M, Goetghebuer T, Weiss HA, Ota MO, Schlegel-Hauter SE, et al. Council Gambia Twin Study: predominant influence of environmental determinants on the persistence and avidity maturation of antibody responses to vaccines in infants. J Infect Dis (2006) 193(11):1598-605. doi:10.1086/503775

23. Feleszko W, Jaworska J, Rha RD, Steinhausen S, Avagyan A, Jaudszus A, et al. Probiotic-induced suppression of allergic sensitization and airway inflammation is associated with an increase of $\mathrm{T}$ regulatory-dependent mechanisms in a murine model of asthma. Clin Exp Allergy (2007) 37(4):498-505. doi:10.1111/j.1365-2222.2006.02629.x

24. de Roock S, van Elk M, van Dijk ME, Timmerman HM, Rijkers GT, Prakken BJ, et al. Lactic acid bacteria differ in their ability to induce functional regulatory T cells in humans. Clin Exp Allergy (2010) 40(1):103-10. doi:10.1111/j.13652222.2009.03344.x 
25. Lopez P, Gonzalez-Rodriguez I, Sanchez B, Gueimonde M, Margolles A, Suarez A. Treg-inducing membrane vesicles from Bifidobacterium bifidum LMG13195 as potential adjuvants in immunotherapy. Vaccine (2012) 30(5):825-9. doi:10. 1016/j.vaccine.2011.11.115

26. Smelt MJ, de Haan BJ, Bron PA, van Swam I, Meijerink M, Wells JM, et al. $L$. plantarum, L. salivarius, and L. lactis attenuate Th2 responses and increase Treg frequencies in healthy mice in a strain dependent manner. PLoS One (2012) 7(10):e47244. doi:10.1371/journal.pone.0047244

27. Rutten NB, Besseling-van der Vaart I, Klein M, de Roock S, Vlieger AM, Rijkers GT. In vitro assessment of the immunomodulatory effects of multispecies probiotic formulations for management of allergic diseases. Benef Microbes (2011) 2(3):183-92. doi:10.3920/BM2011.0012

28. Josefowicz SZ, Lu LF, Rudensky AY. Regulatory T cells: mechanisms of differentiation and function. Annu Rev Immunol (2012) 30:531-64. doi:10.1146/annurev. immunol.25.022106.141623

29. Lesiak A, Smolewski P, Sobolewska-Sztychny D, Sysa-Jedrzejowska A, Narbutt J. The role of T-regulatory cells and toll-like receptors 2 and 4 in atopic dermatitis. Scand J Immunol (2012) 76(4):405-10. doi:10.1111/j.1365-3083.2012.02739.x

30. Kalliomaki M, Salminen S, Arvilommi H, Kero P, Koskinen P, Isolauri E. Probiotics in primary prevention of atopic disease: a randomised placebo-controlled trial. Lancet (2001) 357(9262):1076-9. doi:10.1016/S0140-6736(00)04259-8

31. Rautava S, Kalliomaki M, Isolauri E. Probiotics during pregnancy and breastfeeding might confer immunomodulatory protection against atopic disease in the infant. J Allergy Clin Immunol (2002) 109(1):119-21. doi:10.1067/mai.2002. 120273

32. Huurre A, Laitinen K, Rautava S, Korkeamaki M, Isolauri E. Impact of maternal atopy and probiotic supplementation during pregnancy on infant sensitization: a double-blind placebo-controlled study. Clin Exp Allergy (2008) 38(8):1342-8. doi:10.1111/j.1365-2222.2008.03008.x

33. Prescott SL, Wickens K, Westcott L, Jung W, Currie H, Black PN, et al. Supplementation with Lactobacillus rhamnosus or Bifidobacterium lactis probiotics in pregnancy increases cord blood interferon-gamma and breast milk transforming growth factor-beta and immunoglobin A detection. Clin Exp Allergy (2008) 38(10):1606-14. doi:10.1111/j.1365-2222.2008.03061.x

34. Ismail IH, Licciardi PV, Oppedisano F, Boyle RJ, Tang ML. Relationship between breast milk sCD14, TGF-betal and total IgA in the first month and development of eczema during infancy. Pediatr Allergy Immunol (2013) 24(4):352-60. doi:10.1111/pai.12075

35. Khosravi A, Mazmanian SK. Disruption of the gut microbiome as a risk factor for microbial infections. Curr Opin Microbiol (2013) 16(2):221-7. doi:10.1016/ j.mib.2013.03.009

36. Rautava S, Luoto R, Salminen S, Isolauri E. Microbial contact during pregnancy, intestinal colonization and human disease. Nat Rev Gastroenterol Hepatol (2012) 9(10):565-76. doi:10.1038/nrgastro.2012.144

37. Grzeskowiak L, Gronlund MM, Beckmann C, Salminen S, von Berg A, Isolauri E. The impact of perinatal probiotic intervention on gut microbiota: double-blind placebo-controlled trials in Finland and Germany. Anaerobe (2012) 18(1):7-13. doi:10.1016/j.anaerobe.2011.09.006

38. Rinne M, Kalliomaki M, Salminen S, Isolauri E. Probiotic intervention in the first months of life: short-term effects on gastrointestinal symptoms and longterm effects on gut microbiota. J Pediatr Gastroenterol Nutr (2006) 43(2):200-5. doi:10.1097/01.mpg.0000228106.91240.5b

39. Osborn DA, Sinn JK. Probiotics in infants for prevention of allergic disease and food hypersensitivity. Cochrane Database Syst Rev (2007) (4):CD006475.

40. Boyle RJ, Bath-Hextall FJ, Leonardi-Bee J, Murrell DF, Tang ML. Probiotics for treating eczema. Cochrane Database Syst Rev (2008) (4):CD006135. doi:10.1002/14651858.CD006135.pub2

41. Ismail IH, Licciardi PV, Tang ML. Probiotic effects in allergic disease. J Paediatr Child Health (2013) 49(9):709-15. doi:10.1111/jpc.12175

42. Lahtinen SJ, Boyle RJ, Kivivuori S, Oppedisano F, Smith KR, Robins-Browne $\mathrm{R}$, et al. Prenatal probiotic administration can influence Bifidobacterium microbiota development in infants at high risk of allergy. J Allergy Clin Immunol (2009) 123(2):499-501. doi:10.1016/j.jaci.2008.11.034
43. Ferreira RB, Antunes LC, Finlay BB. Should the human microbiome be considered when developing vaccines? PLoS Pathog (2010) 6(11):e1001190. doi:10.1371/journal.ppat.1001190

44. Licciardi PV, Tang ML. Vaccine adjuvant properties of probiotic bacteria. Discov Med (2011) 12(67):525-33.

45. de Vrese M, Rautenberg P, Laue C, Koopmans M, Herremans T, Schrezenmeir J. Probiotic bacteria stimulate virus-specific neutralizing antibodies following a booster polio vaccination. Eur J Nutr (2005) 44(7):406-13. doi:10.1007/s00394004-0541-8

46. Fang H, Elina T, Heikki A, Seppo S. Modulation of humoral immune response through probiotic intake. FEMS Immunol Med Microbiol (2000) 29(1):47-52. doi:10.1111/j.1574-695X.2000.tb01504.x

47. Olivares M, Diaz-Ropero MP, Sierra S, Lara-Villoslada F, Fonolla J, Navas M, et al. Oral intake of Lactobacillus fermentum CECT5716 enhances the effects of influenza vaccination. Nutrition (2007) 23(3):254-60. doi:10.1016/j.nut.2007. 01.004

48. Bosch M, Mendez M, Perez M, Farran A, Fuentes MC, Cune J. Lactobacillus plantarum CECT7315 and CECT7316 stimulate immunoglobulin production after influenza vaccination in elderly. Nutr Hosp (2012) 27(2):504-9. doi:10.1590/S0212-16112012000200023

49. Soh SE, Ong DQ, Gerez I, Zhang X, Chollate P, Shek LP, et al. Effect of probiotic supplementation in the first 6 months of life on specific antibody responses to infant Hepatitis B vaccination. Vaccine (2010) 28(14):2577-9. doi:10.1016/j.vaccine.2010.01.020

50. Mullie C, Yazourh A, Thibault H, Odou MF, Singer E, Kalach N, et al. Increased poliovirus-specific intestinal antibody response coincides with promotion of Bifidobacterium longum-infantis and Bifidobacterium breve in infants: a randomized, double-blind, placebo-controlled trial. Pediatr Res (2004) 56(5):791-5. doi:10.1203/01.PDR.0000141955.47550.A0

51. Khan AA, Zahidie A, Rabbani F. Interventions to reduce neonatal mortality from neonatal tetanus in low and middle income countries - a systematic review. BMC Public Health (2013) 13(1):322. doi:10.1186/1471-2458-13-322

52. O’Brien KL, Wolfson LJ, Watt JP, Henkle E, Deloria-Knoll M, McCall N, et al. Burden of disease caused by Streptococcus pneumoniae in children younger than 5 years: global estimates. Lancet (2009) 374(9693):893-902. doi:10.1016/S01406736(09)61204-6

53. Wilson-Welder JH, Torres MP, Kipper MJ, Mallapragada SK, Wannemuehler MJ, Narasimhan B. Vaccine adjuvants: current challenges and future approaches. J Pharm Sci (2009) 98(4):1278-316. doi:10.1002/jps.21523

54. Stam J, van Stuijvenberg M, Garssen J, Knipping K, Sauer PJ. A mixture of three prebiotics does not affect vaccine specific antibody responses in healthy term infants in the first year of life. Vaccine (2011) 29(44):7766-72. doi:10.1016/j.vaccine.2011.07.110

Conflict of Interest Statement: The authors declare that the research was conducted in the absence of any commercial or financial relationships that could be construed as a potential conflict of interest.

Received: 02 July 2013; accepted: 04 November 2013; published online: 26 November 2013.

Citation: Licciardi PV, Ismail IH, Balloch A, Mui M, Hoe E, Lamb K and Tang MLK (2013) Maternal supplementation with LGG reduces vaccine-specific immune responses in infants at high-risk of developing allergic disease. Front. Immunol. 4:381. doi: 10.3389/fimmu.2013.00381

This article was submitted to Immunotherapies and Vaccines, a section of the journal Frontiers in Immunology.

Copyright (C) 2013 Licciardi, Ismail, Balloch, Mui, Hoe, Lamb and Tang. This is an open-access article distributed under the terms of the Creative Commons Attribution License (CC BY). The use, distribution or reproduction in other forums is permitted, provided the original author(s) or licensor are credited and that the original publication in this journal is cited, in accordance with accepted academic practice. No use, distribution or reproduction is permitted which does not comply with these terms. 


\section{APPENDIX}

Table A1A | Summary of the vaccine-specific IgG responses following adjustment for eczema and atopy

\begin{tabular}{lllll}
\hline & & & Adjusted \\
\cline { 3 - 5 } Vaccine & \multicolumn{1}{c}{ Unadjusted $^{\mathbf{a}}$} & IgE-eczema (at 12 months) & IgE-eczema (ever) & Atopy \\
\hline PCV7-4 & $0.47(0.21) ; p=0.027$ & $0.51(0.21) ; p=0.019$ & $0.50(0.21) ; p=0.022$ & $0.50(0.21) ; p=0.023$ \\
PCV7-6B & $0.43(0.20) ; p=0.040$ & $0.48(0.21) ; p=0.025$ & $0.50(0.21) ; p=0.020$ & $0.45(0.21) ; p=0.040$ \\
PCV7-9V & $0.39(0.22) ; p=0.085$ & $0.45(0.23) ; p=0.055$ & $0.44(0.23) ; p=0.060$ & $0.47(0.23) ; p=0.040$ \\
PCV7-14 & $0.19(0.23) ; p=0.413$ & $0.23(0.24) ; p=0.344$ & $0.24(0.24) ; p=0.316$ & $0.23(0.24) ; p=0.337$ \\
PCV7-18C & $0.48(0.22) ; p=0.032$ & $0.51(0.22) ; p=0.027$ & $0.52(0.22) ; p=0.024$ & $0.53(0.22) ; p=0.021$ \\
PCV7-19F & $0.47(0.22) ; p=0.041$ & $0.47(0.23) ; p=0.047$ & $0.48(0.23) ; p=0.045$ & $0.47(0.23) ; p=0.047$ \\
PCV7-23F & $0.54(0.22) ; p=0.019$ & $0.57(0.23) ; p=0.017$ & $0.58(0.23) ; p=0.015$ & $0.54(0.23) ; p=0.022$ \\
Tetanus toxoid & $0.60(0.289) ; p=0.042$ & $0.60(0.30) ; p=0.052$ & $0.63(0.30) ; p=0.039$ & $0.64(0.30) ; p=0.037$ \\
Hib & $0.56(0.44) ; p=0.212$ & $0.50(0.48) ; p=0.306$ & $0.51(0.48) ; p=0.293$ & $0.57(0.47) ; p=0.234$ \\
\hline
\end{tabular}

Data represents the regression coefficient and standard errors in brackets. Regression coefficient refers to the group as a predictor for each of the outcome measures where the baseline for comparison is the LGG group ( $n=31$ ).

For example, considering PCV7-4 (coefficient of 0.47 in the unadjusted analysis) refers that the mean response for PCV7-4 in the control group (Placebo) is 0.49 times higher than the mean response for the LGG group.

anadjusted analysis after removing missing data for eczema and atopy variables ( $N=30 L G G ; N=30$ Placebo). This refers to the analysis between the $L G G$ and placebo groups after removal of vaccine immune responses for the one infant where the eczema/atopy status was not available.

Table A1B | Summary of the vaccine-specific IgG responses following adjustment for yogurt intake.

Yogurt intake

\begin{tabular}{lcr} 
Vaccine & \multicolumn{1}{c}{ Unadjusted $^{\mathbf{a}}$} & Adjusted \\
\hline PCV7-4 & $0.66(0.22) ; p=0.005$ & $0.56(0.22) ; p=0.015$ \\
PCV7-6B & $0.28(0.23) ; p=0.229$ & $0.20(0.23) ; p=0.390$ \\
PCV7-9V & $0.56(0.24) ; p=0.025$ & $0.53(0.25) ; p=0.041$ \\
PCV7-14 & $0.32(0.25) ; p=0.200$ & $0.31(0.26) ; p=0.229$ \\
PCV7-18C & $0.63(0.24) ; p=0.011$ & $0.59(0.24) ; p=0.019$ \\
PCV7-19F & $0.56(0.24) ; p=0.024$ & $0.52(0.25) ; p=0.042$ \\
PCV7-23F & $0.71(0.24) ; p=0.005$ & $0.67(0.25) ; p=0.009$ \\
Tetanus toxoid & $0.64(0.33) ; p=0.055$ & $0.68(0.34) ; p=0.047$ \\
Hib & $0.50(0.46) ; p=0.286$ & $0.35(0.48) ; p=0.463$
\end{tabular}

Data represents the regression coefficient and standard errors in brackets.

a Unadjusted analysis after removing missing data for yogurt intake ( $N=25 L G G ; N=26$ Placebo).

Table A2A | Summary of the PCV7 serotype-specific lgG responses $\geq 0.35 \mu \mathrm{g} / \mathrm{ml}$ following adjustment for eczema and atopy

\section{Adjusted}

\begin{tabular}{lllll} 
& \multicolumn{1}{c}{ Unadjusted $^{\mathbf{a}}$} & IgE-eczema (at 12 months) & \multicolumn{1}{c}{ IgE-eczema (ever) } & Atopy \\
\hline PCV7-4 & $3.29(1.08,9.95) ; p=0.035$ & $3.27(1.05,10.19) ; p=0.041$ & $3.30(1.09,10.00) ; p=0.035$ & $3.47(1.10,10.96) ; p=0.034$ \\
PCV7-6B & $2.32(0.72,7.41) ; p=0.157$ & $3.04(0.89,10.35) ; p=0.075$ & $2.36(0.73,7.61) ; p=0.149$ & $2.43(0.73,8.09) ; p=0.147$ \\
PCV7-9V & $3.50(1.11,11.02) ; p=0.032$ & $4.07(1.23,13.49) ; p=0.022$ & $3.62(1.14,11.51) ; p=0.030$ & $4.27(1.26,14.43) ; p=0.019$ \\
PCV7-14 & NA & NA & NA & NA \\
PCV7-18C & $2.41(0.82,7.10) ; p=0.111$ & $2.30(0.76,6.96) ; p=0.142$ & $2.44(0.82,7.23) ; p=0.107$ & $2.93(0.92,9.35) ; p=0.069$ \\
PCV7-19F & $4.46(0.47,42.51) ; p=0.194$ & $4.96(0.50,48.92) ; p=0.170$ & $4.48(0.47,42.76) ; p=0.192$ & $4.56(0.46,45.46) ; p=0.196$ \\
PCV7-23F & $5.21(1.28 ; 21.24) ; p=0.021$ & $5.25(1.25,22.03) ; p=0.024$ & $5.21(1.28,21.24) ; p=0.021$ & $4.67(1.12,19.55) ; p=0.035$
\end{tabular}

Data represents the Odds Ratio and 95\% confidence intervals; NA, not assessed due to co-linearity issues.

a Unadjusted analysis after removing missing data for eczema and atopy variables ( $N=30 \mathrm{LGG}$; $N=30$ Placebo). 
Table A2B | Summary of the PCV7 serotype-specific lgG responses $\geq 0.35 \mu \mathrm{g} / \mathrm{ml}$ following adjustment for yogurt intake

\begin{tabular}{llr}
\hline & & \multicolumn{1}{c}{ Yogurt intake } \\
\cline { 2 - 3 } Vaccine & \multicolumn{1}{c}{ Unadjusted $^{\mathbf{a}}$} & \multicolumn{1}{c}{ Adjusted } \\
\hline PCV7-4 & $4.07(1.25,13.24) ; p=0.020$ & $3.63(1.09,12.10) ; p=0.036$ \\
PCV7-6B & $1.98(0.55,7.16) ; p=0.300$ & $1.92(0.51,7.16) ; p=0.333$ \\
PCV7-9V & $5.35(1.52,18.75) ; p=0.009$ & $5.36(1.48,19.36) ; p=0.010$ \\
PCV7-14 & $N A$ & $N A$ \\
PCV7-18C & $2.71(0.82,9.00) ; p=0.103$ & $2.75(0.80,9.39) ; p=0.107$ \\
PCV7-19F & $4.76(0.49,45.95) ; p=0.177$ & $3.60(0.35,37.09) ; p=0.281$ \\
PCV7-23F & $6.02(1.43,25.40) ; p=0.014$ & $5.74(1.33,24.79) ; p=0.019$
\end{tabular}

Data represents the Odds Ratio and 95\% confidence intervals; NA, not assessed due to co-linearity issues.

anadjusted analysis after removing missing data for yogurt intake ( $N=25 L G G ; N=26$ Placebo).

Table A3A | Summary of the PCV7 serotype-specific lgG responses $\geq 1.0 \mu \mathrm{g} / \mathrm{ml}$ following adjustment for eczema and atopy.

\begin{tabular}{lllll}
\hline & & & \multicolumn{1}{c}{ Adjusted } \\
\cline { 3 - 5 } Vaccine & \multicolumn{1}{c}{ Unadjusted $^{\mathbf{a}}$} & IgE-eczema (at 12 months) & IgE-eczema (ever) & Atopy \\
\hline PCV7-4 & $1.30(0.31,5.40) ; p=0.718$ & $1.30(0.30,5.64) ; p=0.726$ & $1.28(0.31,5.36) ; p=0.731$ & $1.50(0.34,6.65) ; p=0.591$ \\
PCV7-6B & $2.32(0.72,7.41) ; p=0.157$ & $2.21(0.67,7.27) ; p=0.193$ & $2.32(0.72,7.41) ; p=0.157$ & $2.24(0.68,7.40) ; p=0.187$ \\
PCV7-9V & $1.22(0.36,4.17) ; p=0.754$ & $1.23(0.35,4.36) ; p=0.752$ & $1.20(0.35,4.14) ; p=0.776$ & $1.66(0.44,6.25) ; p=0.456$ \\
PCV7-14 & $1.25(0.34,4.64) ; p=0.739$ & $1.20(0.31,4.63) ; p=0.794$ & $1.24(0.33,4.62) ; p=0.746$ & $1.25(0.32,4.82) ; p=0.751$ \\
PCV7-18C & $1.56(0.24,10.05) ; p=0.643$ & NA & NA & NA \\
PCV7-19F & $2.62(0.92,7.46) ; p=0.072$ & $2.32(0.79,6.79) ; p=0.125$ & $2.61(0.92,7.45) ; p=0.073$ & $2.49(0.85,7.32) ; p=0.096$ \\
PCV7-23F & $2.00(0.62,6.46) ; p=0.247$ & $2.16(0.64,7.32) ; p=0.217$ & $1.98(0.61,6.47) ; p=0.256$ & $2.19(0.64,7.43) ; p=0.210$ \\
\end{tabular}

Data represents the Odds Ratio and 95\% confidence intervals; NA, not assessed due to co-linearity issues.

a Unadjusted analysis after removing missing data for eczema and atopy variables ( $N=30 L G G ; N=30$ Placebo).

Table A3B | Summary of the PCV7 serotype-specific IgG responses $\geq 1.0 \mu \mathrm{g} / \mathrm{ml}$ following adjustment for yogurt intake.

\begin{tabular}{llr}
\hline & & \multicolumn{1}{c}{ Yogurt intake } \\
\cline { 2 - 3 } Vaccine & \multicolumn{1}{c}{ Unadjusted $^{\mathbf{a}}$} & Adjusted \\
\hline PCV7-4 & $2.74(0.48,15.65) ; p=0.257$ & $2.17(0.35,13.39) ; p=0.404$ \\
PCV7-6B & $1.41(0.41,4.86) ; p=0.589$ & $1.11(0.30,4.11) ; p=0.873$ \\
PCV7-9V & $1.47(0.40,5.45) ; p=0.561$ & $1.20(0.31,4.68) ; p=0.797$ \\
PCV7-14 & $1.33(0.35,5.06) ; p=0.679$ & $1.33(0.34,5.25) ; p=0.683$ \\
PCV7-18C & $0.96(0.12,7.38) ; p=0.967$ & $0.80(0.10,6.50) ; p=0.834$ \\
PCV7-19F & $2.57(0.80,8.23) ; p=0.112$ & $2.20(0.66,7.30) ; p=0.199$ \\
PCV7-23F & $2.78(0.73,10.62) ; p=0.135$ & $2.31(0.57,9.29) ; p=0.238$
\end{tabular}

Data represents the Odds Ratio and 95\% confidence intervals; NA, not assessed due to co-linearity issues.

${ }^{a}$ Unadjusted analysis after removing missing data for yogurt intake ( $N=25 L G G ; N=26$ Placebo). 